\title{
IMPACTO DO USO DO EXERGAME SOBRE O RISCO CARDIOVASCULAR AVALIADO PELA PCR ULTRASSENSÍVEL: UM ESTUDO COM ADOLESCENTES COM EXCESSO DE PESO
}

\author{
IMPACT OF EXERGAME ON CARDIOVASCULAR RISK ASSESSED \\ BY THE ULTRA-SENSITIVE C-REACTIVE PROTEIN: A STUDY WITH \\ OVERWEIGHT ADOLESCENTS
}

\author{
Fernanda Caroline Tavares de Melo ${ }^{1}$ \\ Naryelle da Rocha Silva ${ }^{2}$ \\ Morgana Monteiro Pimentel ${ }^{3}$ \\ Geisielly Raquel da Cruz Aguiar ${ }^{4}$ \\ Gabrielle Sousa Marques ${ }^{5}$ \\ Danielle Franklin de Carvalho ${ }^{6}$
}

RESUMO: OBJETIVO: tendo em vista que os índices de obesidade e sobrepeso se fazem cada vez mais alarmantes, inclusive em crianças e adolescentes, torna-se necessário o uso de novas abordagem que estimulem o exercício em tal faixa etária, como o uso de videogames ativos (exergames). Desta forma, este estudo buscou verificar o impacto do exergame no risco cardiovascular avaliado pela Proteína CReativa ultrassensível (PCR-u) em adolescentes com sobrepeso ou obesidade de Campina Grande-PB. MÉTODOS: estudo de intervenção quase experimental realizado com 48 adolescentes (15 a 19 anos) com sobrepeso ou obesidade matriculados em escolas públicas de ensino médio. A intervenção foi realizada durante oito semanas, 3 vezes por semana, com sessões de 50 minutos, através da plataforma XBOX 360, com acessório Kinect $\left(\right.$ Microsoft $^{\circledR}$ ) e o Just Dance foi o jogo selecionado. Os dados foram analisados através do SPSS 22.0 e para todas as análises foi adotado um nível de significância de 5\%. RESULTADOS: amostra composta majoritariamente pelo sexo feminino $(60,4 \%)$, de classes econômicas C, D e E $(56,3 \%)$, autorreferida de cor não branca $(79,2 \%)$ e com sobrepeso $(70,8 \%)$. No

\footnotetext{
${ }^{1}$ Graduada em Enfermagem. Universidade Estadual da Paraíba, Campina Grande, Paraíba, Brasil.

${ }^{2}$ Mestre em Saúde Pública. Universidade de Pernambuco, Recife, Pernambuco, Brasil.

${ }^{3}$ Graduada em Enfermagem. Universidade Estadual da Paraíba, Campina Grande, Paraíba, Brasil.

${ }^{4}$ Graduada em Enfermagem. Universidade Estadual da Paraíba, Campina Grande, Paraíba, Brasil.

${ }^{5}$ Graduada em Fisioterapia. Universidade Estadual da Paraíba, Campina Grande, Paraíba, Brasil.

${ }^{6}$ Doutora em Saúde da Criança e do Adolescente. Universidade Estadual da Paraíba, Campina Grande, Paraíba, Brasil.
} 
início do estudo, $24,1 \%$ dos adolescentes foram classificados como muito ativos, $38,9 \%$ como ativos, e $22,2 \%$ como insuficientemente ativos. Embora significativo o aumento no nível de atividade física proporcionado pela intervenção, não foi registrada alteração estatisticamente significante nos níveis de PCR-u. CONCLUSÃO: o exergame foi capaz de produzir melhoria no nível de atividade física, mas não na PCR-u. Sugere-se que estudos com períodos de intervenção maiores possam ser realizados para melhor avaliação.

Palavras chave: Adolescente; Obesidade; Jogos de Vídeo.

ABSTRACT: OBJECTIVE: Given that obesity and overweight rates are becoming increasingly alarming, including in children and adolescents, it is necessary to use new approaches that stimulate exercise in such age group, such as the use of active video games (exergames). This study sought to verify the impact of the exergame on cardiovascular risk assessed by ultra-sensitive C-Reactive Protein (URC) in overweight or obese adolescents in Campina Grande/PB. METHODS: $A$ almost experimental intervention study with 48 adolescents (15 to 19 years old) who were overweight or obese enrolled in public high schools. The intervention was performed for eight weeks, 3 times a week, with sessions of 50 minutes, through the platform XBOX 360 platform, with Kinect accessory (Microsoft $\circledast$ ) and Just Dance was the game selected. The data were analyzed through SPSS 22.0 and, for all analyzes, was adopted a significance level of 5\%. RESULTS: Sample composed mostly by female sex (60.4\%), of economic classes $C, D$ and $E(56.3 \%)$, self-referred non-white (79.2\%) and overweight (70.8\%). At the beginning of the study, $24.1 \%$ of the adolescents were classified as very active, $38.9 \%$ as active, and $22.2 \%$ as insufficiently active. Although significant increase in the level of physical activity provided by the intervention, there was no statistically significant change in the levels of U-CRP. CONCLUSION: the exergame was able to produce improvement in the level of physical activity, but not in the PCR-u. It is suggested that studies with longer intervention periods can be performed for a better evaluation.

Keywords: Adolescent; Obesity; Video Games. 


\section{INTRODUÇÃO}

O aumento no consumo de alimentos ricos em energia e gordura, bem como da inatividade física decorrente de formas de trabalho sedentárias, do avanço dos meios de transporte e aumento da urbanização, são características presentes a nível global que favorecem a ocorrência de um desequilíbrio energético entre o consumo e o gasto calórico, uma das causas fundamentais da obesidade e do excesso de peso (WHO, 2018a).

Comparando as taxas de obesidade entre os anos de 1975 e 2016 percebese que os casos entre crianças e adolescentes aumentaram de menos de $1 \%$ (aproximadamente cinco milhões de meninas e seis milhões de meninos) para 6\% (50 milhões) e 8\% (74 milhões) em meninas e meninos, respectivamente, atingindo um total de 124 milhões de obesos de 5 a 19 anos de idade em 2016 (WHO, 2018b).

Além de ocasionar, ainda na infância, dificuldades respiratórias, aumento do risco de fraturas, hipertensão, resistência à insulina e efeitos psicológicos, a obesidade infantil predispõe $\mathrm{o}$ indivíduo à obesidade, morte prematura, e incapacidade na vida adulta (WHO, 2018a). Por sua vez, a doença aterosclerótica também já é descrita por alguns estudos iniciando no período da infância, particularmente em crianças que apresentem fatores de risco cardiovascular (RCV) (PIRES et al; 2015).

O mecanismo da inflamação é apontado como mecanismo chave na patogênese dos vários estágios da aterosclerose, e devido à dificuldade de mensuração do processo aterosclerótico, surge o interesse em investigar os biomarcadores de inflamação, proteínas plasmáticas que podem ser quantificadas a partir do sangue periférico, como a Proteína C- Reativa (PCR), considerada a mais estudada na doença coronariana (SILVA, LACERDA, 2012).

Considerando que a prática de atividade física (AF) reduz o risco de diabetes, câncer, depressão, e o próprio RCV, a inatividade física constitui um fator de risco para as doenças não transmissíveis (DNT), entretanto, se faz cada vez mais 
presente entre a população, com cerca de $23 \%$ dos adultos e $81 \%$ dos adolescentes tidos como não suficientemente ativos (WHO, 2018c).

Segundo Freitas et al (2014), cada vez mais as telas de computador, televisão, videogames e tablets têm tomado o tempo da população adolescente. Assim, transformar o modelo de jogo sedentário em um jogo ativo de exergames, jogos que exigem movimentos gerais do corpo para seu correto funcionamento, surge como um método promissor para incentivar a prática de atividade física entre tal população e intervir sobre a obesidade, tendo em vista que podem aumentar o gasto calórico, coordenação e habilidades do jogador (STAIANO, CALVERT; 2011).

Nessa perspectiva, diante dos altos índices de sobrepeso e obesidade, bem como de sua relação direta com o risco cardiovascular já no período da infância e a influência de novos métodos que estimulem a prática de AF, este estudo tem por objetivo investigar o impacto do exergame sobre o risco cardiovascular, avaliado pela PCR-u, em adolescentes com excesso de peso.

\section{MÉTODOS}

Estudo de intervenção quase experimental realizado com uma amostra de 48 adolescentes com sobrepeso ou obesidade matriculados em escolas públicas de ensino médio estaduais localizadas no município de Campina Grande, Paraíba, e com faixa etária de 15 a 19 anos.

A pesquisa foi realizada em duas escolas de grande porte (igual ou superior a 500 alunos) (TENÓRIO et al; 2010) situadas na zona urbana da cidade.

A triagem nas escolas aconteceu no período de junho e julho de 2016; as coletas de dados aconteceram em três períodos distintos (agosto, novembro e dezembro de 2016) e as intervenções ocorreram no período de setembro a novembro de 2016. A escolha das escolas se deu por conveniência, de acordo com a prevalência de adolescentes com excesso de peso.

Adotou-se como critérios de inclusão: adolescente estar regularmente matriculado em escolas de grande porte da rede pública de ensino estadual na zona 
urbana de Campina Grande-PB; estar cursando o primeiro ou o segundo ano do ensino médio nas escolas selecionadas; estar dentro da faixa etária determinada e apresentar excesso de peso corporal (sobrepeso ou obesidade).

No que diz respeito aos critérios de exclusão: limitação motora ou mental que impedisse a participação nas atividades da intervenção; possuir alguma alteração metabólica severa que exigisse o uso de medicamentos ou tratamento específico que alterasse o metabolismo do perfil lipídico; possuir asma com crise recente (dois meses anteriores à coleta de dados) e/ou relato de broncoespasmo induzido pelo exercício; ser usuário de videogame ativo; e gestantes. No caso de desenvolvimento de algum dos critérios de exclusão ao longo do estudo, isso implicaria no desligamento do adolescente da pesquisa.

A intervenção foi realizada com exergame através da prática de exercícios com auxílio de um videogame ativo e foi supervisionada e monitorizada por equipe devidamente treinada. Obteve frequência semanal de três vezes por semana (nas escolas) e duração de 50 minutos cada sessão, por um período de oito semanas. Os jogos foram disponibilizados em salas destinadas para tal finalidade nas escolas selecionadas, em horários nos turnos da manhã e tarde. Tendo sido utilizada a plataforma XBOX 360, com acessório Kinect (Microsoft ${ }^{\circledR}$ ), e o jogo Just Dance dos anos 2014 e 2016.

A determinação quantitativa da PCR-u foi realizada no soro através do método de quimioluminescência. Amostras com valores $\geq 10 \mathrm{mg} / \mathrm{L}$ foram excluídas da análise por sugerirem processo infeccioso ou inflamatório agudo (LANDE et al; 2008).

Realizou-se também uma análise descritiva das variáveis sociodemográficas (idade em anos completos; sexo masculino ou feminino; cor autorreferida como branca, parda, preta, indígena ou amarela e classe econômica ( $A, B, C, D$ e E) identificada pelo critério brasileiro de classificação (ABEP, 2012).

O estado nutricional foi classificado através do Índice de Massa Corporal (IMC), de acordo com as recomendações da Organização Mundial de Saúde (OMS) para cada faixa etária, considerando-se para menores de 18 anos: sobrepeso (IMC $\geq$ +1 e $<$ Escore-Z +2), obesidade (IMC $\geq$ Escore-Z +2 e IMC < Escore-Z +3) e obesidade acentuada (IMC $\geq$ Escore-Z +3); já para os maiores de 18 anos (em 
$\mathrm{kg} / \mathrm{m} 2$ ) foi considerado: sobrepeso (IMC $\geq 25,0$ e<30) e obesidade (IMC $\geq 30,0$ ) (ONIS et al; 2007).

O nível de atividade física foi utilizado como variável de controle e avaliado pelo "Questionário Internacional de Atividade Física" (IPAQ), versão curta. O IPAQ é um questionário desenvolvido pela OMS e pelo Centro de Controle e Prevenção de Doenças, que avalia o tipo de atividade física adotado em um certo período de tempo (últimos sete dias) (SAUCEDO-MOLINA et al; 2015).

A classificação da atividade física, segundo esse instrumento, deu-se de acordo com o Centro de Estudos do Laboratório de Aptidão Física de São Caetano do Sul (CELAFISCS), que subdividiu em cinco categorias: muito ativo, ativo, irregularmente ativo $A$, irregularmente ativo $B$ e sedentário. Para efeitos de análise de dados, foi realizada uma reclassificação em dois grupos: "ativos" (muito ativo e ativo) e "não ativos" (irregularmente ativo A, irregularmente ativo B e sedentário). Esse questionário é validado para a utilização em adolescentes (HONG et al; 2012).

Quanto aos procedimentos de análise dos dados, inicialmente foi apresentada a estatística descritiva através da frequência absoluta e relativa para caracterização da população. Para avaliação da associação do uso do exergame com o nível de atividade física foi utilizado o teste de McNemar. Já o impacto do exergame no RCV avaliado pela PCR-u foi avaliado através do teste de Wilcoxon (para variável assimétrica), tendo sido a distribuição das variáveis verificada pelo teste de Kolmogorov-Smirnov. Os dados foram analisados através do SPSS versão 22.0, e para todas as análises foi adotado um nível de significância de $5 \%$.

A pesquisa foi desenvolvida de acordo com a Resolução 466/2012 do Conselho Nacional de Saúde (BRASIL, 2012) e aprovada pelo Comitê de Ética em Pesquisa da Universidade Estadual da Paraíba (CAAE: 56118616.1.0000.5187) em $30 / 05 / 2016$. Foram explicados os procedimentos de pesquisa aos adolescentes e entregue uma carta de esclarecimentos, o termo de consentimento livre e esclarecido (TCLE) e o termo de assentimento (TA). 


\section{RESULTADOS}

Dos 55 adolescentes inicialmente avaliados no estudo, apenas 48 foram avaliados antes e depois da intervenção, três foram excluídos por apresentarem valores de PCR sugestivos de processo infeccioso ou inflamatório agudo $(\geq 10$ $\mathrm{mg} ; \mathrm{L})$, e quatro não completaram o período de intervenção.

Do total, 60,4\% $(n=29)$ eram do sexo feminino, 56,3\% $(n=27)$ pertenciam às classes econômicas C, D e E, e 79,2\% (n=38) se autorreferiram como sendo de cor não branca. Com relação ao estado nutricional, 70,8\% $(n=34)$ apresentavam sobrepeso. A idade média foi de 16,3 \pm 1 ano.

Com relação ao estilo de vida (nível de atividade física e sedentarismo) avaliado antes da intervenção, 24,1\% $(n=12)$ foram classificados como muito ativos, $38,9 \%(n=19)$ como ativos, $14,8 \%(n=7)$ como insuficientemente ativos $A, 11,1 \%$ $(n=5)$ como insuficientemente ativos B e 11,1\% $(n=5)$ como sedentários. Conforme recategorização em dois grupos tivemos: 63\% $(n=30)$ ativos e $37 \%$ não ativos $(n=18)$.

Observou-se que a intervenção aumentou significativamente $(p=0,022)$ o nível de atividade física entre os adolescentes com sobrepeso ou obesidade (Tabela 1).

Tabela 1 - Distribuição dos 48 adolescentes escolares quanto ao nível de atividade física, avaliado pelo IPAQ, antes e depois da intervenção. Campina Grande- PB, 2016.

\begin{tabular}{cccccc}
\hline $\begin{array}{c}\text { Antes da } \\
\text { intervenção }\end{array}$ & \multicolumn{5}{c}{ Depois da intervenção } \\
\\
Não ativos & $\mathbf{N}$ & $\mathbf{n}$ & $\%$ & Ativos \\
Não ativos & 07 & 38,9 & 11 & 61,1 & $0,022^{*}$ \\
Ativos & 02 & 6,7 & 28 & 93,3 & \\
\hline
\end{tabular}

*Teste de McNemar

A PCR-u apresentou distribuição não paramétrica nos dois momentos, sendo avaliada pela mediana e intervalo interquartil. 
As figuras 1 e 2 permitem a visualização da distribuição das medianas, intervalos quartílicos e valores discrepantes da PCR-u antes e depois da intervenção, respectivamente. Tendo sido registrado mediana basal de 0,94 e mediana final de 1,39 , resultando em alteração não estatisticamente significante $(p=0,357)$.

Figura 1 - Distribuição da mediana e intervalo quartílico da PCR-u dos 48 adolescentes escolares antes da intervenção. Campina Grande - PB, 2016.

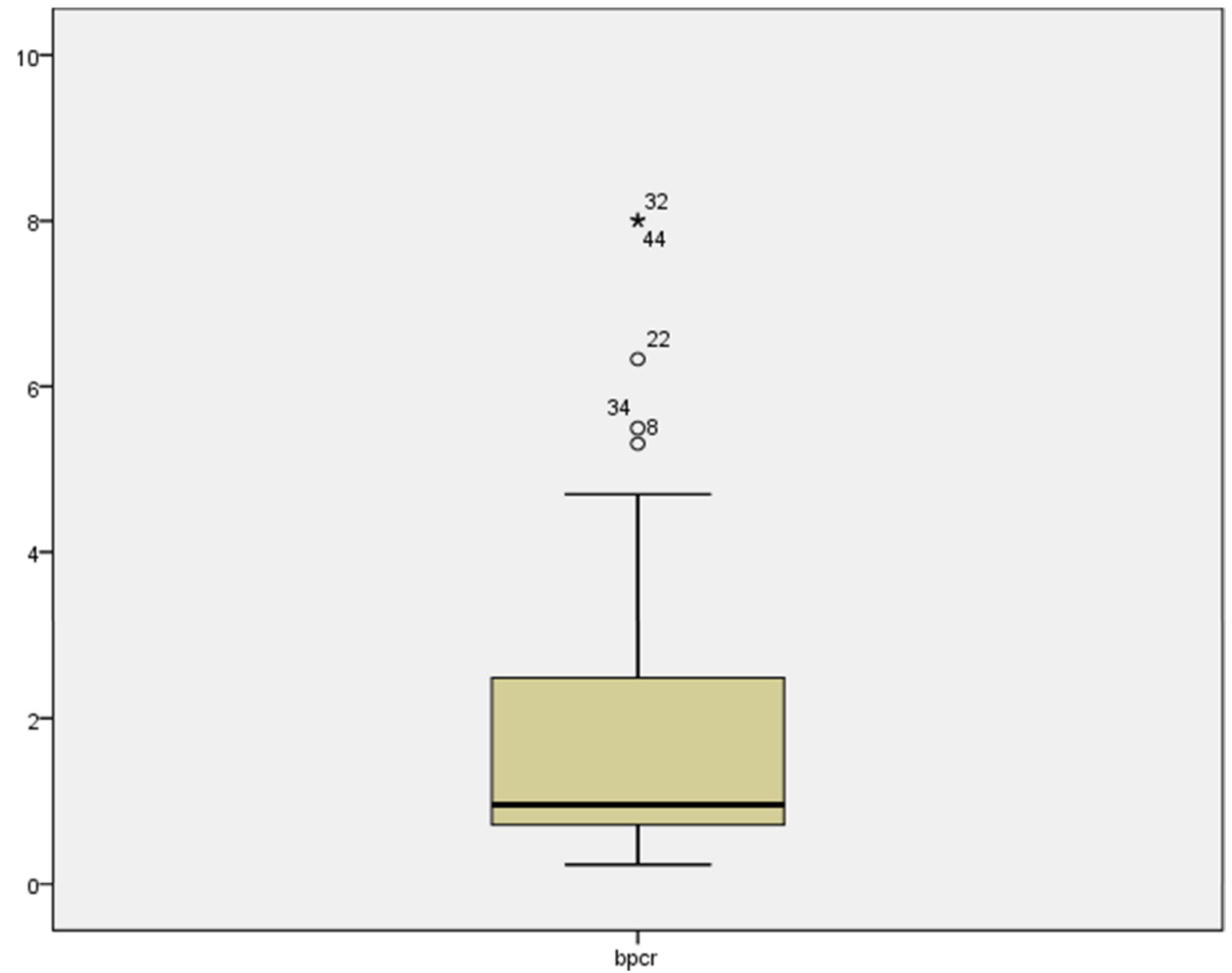


Figura 2 - Distribuição da mediana e intervalo quartílico da PCR-u dos 48 adolescentes escolares depois da intervenção. Campina Grande - PB, 2016.

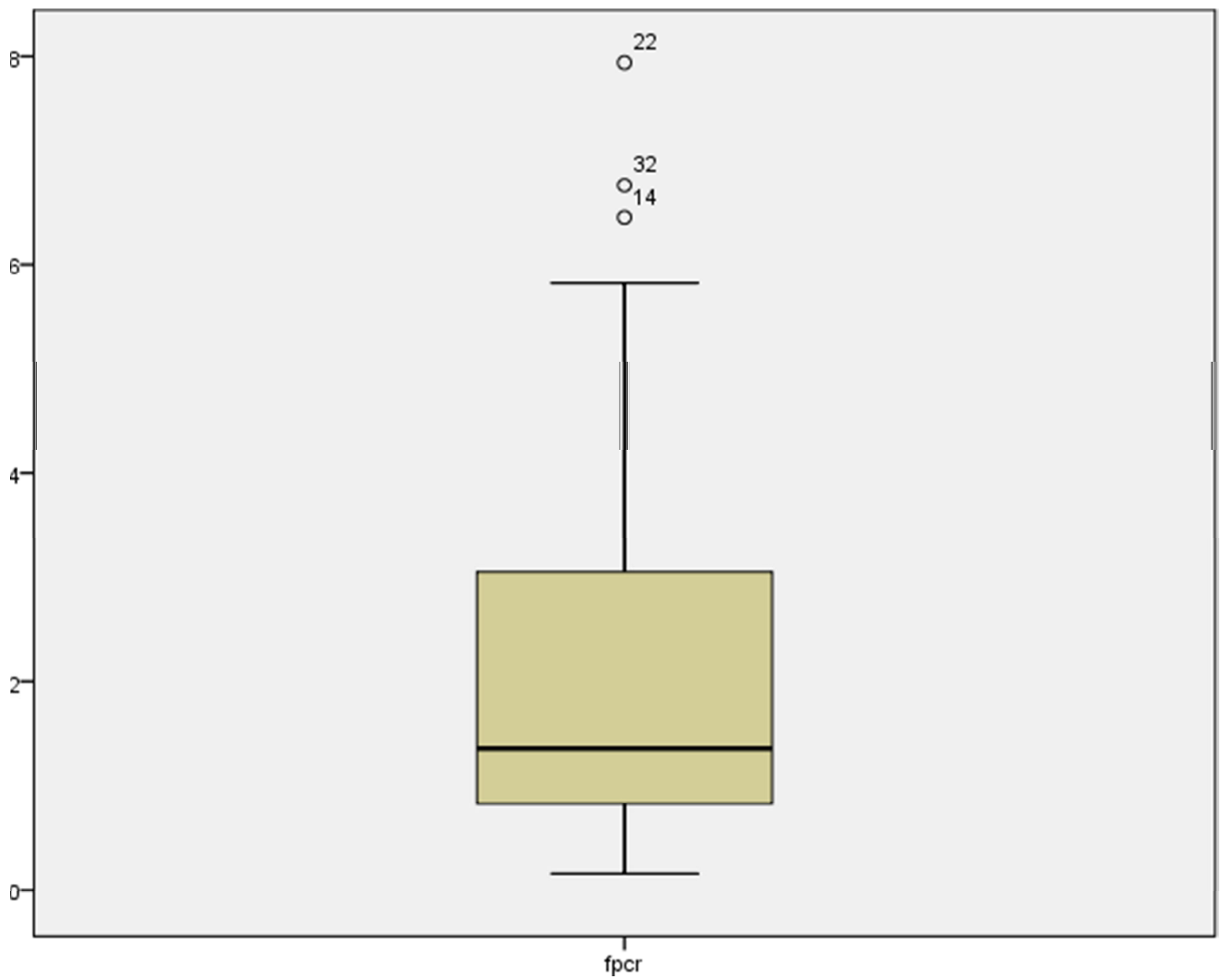

\section{DISCUSSÃO}

Intervir precocemente sobre o excesso de peso e obesidade em crianças e adolescentes, evitando que o estado metabólico/inflamatório desfavorável o acompanhe por anos, ajuda na diminuição da incidência de possíveis comorbidades na fase adulta (NORONHA et al; 2013). Assim, torna-se de suma importância o estímulo à prática de $\mathrm{AF}$ em tal faixa etária.

No presente estudo, a amostra foi composta majoritariamente por participantes do sexo feminino, pelas classes sociais C, D e E, e com classificação 
de sobrepeso para o estado nutricional. População semelhante foi encontrada em estudo realizado com amostra de 184 crianças e adolescentes com sobrepeso e obesidade (2 a 18 anos de idade) que buscou verificar a relação entre a PCR e a pressão arterial, tendo diferido apenas no estado nutricional, em que mais da metade apresentava obesidade grave (NORONHA et al; 2013).

Segundo a $\mathrm{OMS}^{5}$, globalmente, $81 \%$ dos adolescentes que estão nas escolas não são ativos o suficiente. O presente estudo obteve, a partir da avaliação pelo IPAQ, maioria da população ativa (24,1\% muito ativa, $38,9 \%$ ativos), seguido de insuficientemente ativos $(25,9 \%)$ e sedentários (11,1\%). Já estudo também realizado com alunos da rede pública, entretanto com população mais nova (6 a 11 anos de idade), obteve, também pela avaliação do IPAQ, resultados diferentes, com maioria insuficientemente ativos (43,5\%), seguido de ativos $(31,5 \%)$ e sedentários $(25 \%)$ (ALVES et al; 2014). A diferença entre o quantitativo das amostras e as idades das populações avaliadas entre os estudos podem ter relação com tal diferença.

Como esperado, o uso do exergame possibilitou um aumento no nível de atividade física dos participantes, o que corrobora com o estudo de Vojciechowski et al (2017) em que se constatou que a prática de AF com o XBOX 360 Kinect $^{\circledR}$ proporcionou melhora no nível de atividade e da autopercepção do estado de saúde em adultos jovens.

No tocante à PCR, alguns estudos constataram relação entre nível de AF e valores séricos de PCR. Kamal e Ragi (2012) em estudo realizado com crianças normais, crianças obesas sem síndrome metabólica e crianças obesas com síndrome metabólica, após submetê- las à prática de exercício físico 3 vezes/semana, perceberam que, em ambos os grupos de crianças obesas, houve diminuição do nível de PCR após 12 semanas de exercício. Chae et al (2010) observou melhora nos níveis de PCR de crianças coreanas obesas entre 9 e 15 anos, após realização de um programa de exercícios com 90 min, 2 vezes/semana, também por um período de 12 semana de intervenção.

Hamer et al (2012) comprovou a existência de tal relação também a longo prazo, examinando-a durante um período de 10 anos. Em seu estudo, realizado com homens e mulheres com idade média de 49,2 anos, foi relatado associação entre AF 
regular e menores níveis de marcadores inflamatórios, destacando a AF como mecanismo importante na prevenção do estado pró-inflamatório.

Entretanto, no presente estudo, a intervenção com uso do exergame não resultou em alteração estatisticamente significante dos níveis de PCR. Sendo tal resultado encontrado também por outros estudos, como Klenk et al (2013), porém, realizados com outras faixas etárias.

Fatores confundidores relacionados à $A F$ e que são independentemente associados às concentrações de PCR (IMC, idade, relação cintura quadril, e perfil lipídico) dificultam o conhecimento dos mecanismos envolvidos entre a $\mathrm{AF}$ e a redução dos níveis plasmáticos de PCR (QUEIROZ, 2013).

Uma resposta anti-inflamatória é desencadeada no organismo após uma sessão de exercício agudo e atua no metabolismo glicêmico e lipídico, de forma que a prática regular de exercícios pode promover consideráveis reduções nas concentrações plasmáticas de adipocinas pró-inflamatórias (ELIAS et al; 2015). Assim, tendo em vista o impacto do exergame sobre o nível de AF, pode-se pressupor que, em longo prazo, o exercício com auxílio do exergame poderia gerar impacto, também, sobre os níveis de PCR.

\section{CONCLUSÃO}

Os resultados obtidos pelo estudo indicaram que a intervenção realizada com o exergame possibilitou um aumento significativo do nível de atividade física entre os adolescentes com sobrepeso ou obesidade. No entanto, com relação à PCR-u não foi registrada alteração estatisticamente significante entre o período anterior e posterior à intervenção.

Fatores como o período estipulado para realização da intervenção e a não observação dos hábitos alimentares podem ter caracterizado limitações do estudo que devem ser observadas em projetos futuros. 


\section{DECLARAÇÃO DE CONFLITO DE INTERESSE}

Artigo fruto de um trabalho de conclusão de curso apresentado ao curso de Bacharelado em Enfermagem da Universidade Estadual da Paraíba.

\section{FONTE FINANCIADORA DO PROJETO}

Este trabalho recebeu financiamento da Universidade Estadual da Paraíba PROPESQ 2017. [Processo:4.06.01.00-5-415/2017-1]

\section{REFERÊNCIAS BIBLIOGRÁFICAS}

ALVES, M. P. A. et al. Fatores de risco cardiovascular em crianças e adolescentes de uma escola da rede pública do município de Gurupi -TO. Revista Amazônia Science \& Health, v. 2, n. $4,2014 . \quad 2-8, \quad 2018$ Disponível http://www.ojs.unirg.edu.br/index.php/2/article/viewFile/764/290. Acesso em: 06 set. 2018.

Associação Brasileira de Empresas de Pesquisa (ABEP). CCEB: Critério de Classificação Econômica Brasil. São Paulo, 2012.

BRASIL. Conselho Nacional de Saúde (Brasil). Resolução n o 466, de 12 de dezembro de 2012. Brasília: 2012. Disponível em: http://conselho.saude.gov.br/resolucoes/reso_12.htm. Acesso em: CHAE, H. W. et al. Effects of a Structured Exercise Program on Insulin Resistance, Inflammatory Markers and Physical Fitness in Obese Korean Children. Journal of Pediatric Endocrinology and Metabolism, v. 23, n. 10, p. 1065-1072, 2010. Disponível em: https://www.degruyter.com/view/j/jpem.2010.23.issue-10/jpem.2010.168/jpem.2010.168.xml. Acesso em: 15 out. 2018.

ELIAS, R. G. M. et al. Efeito do exercício físico sobre os marcadores inflamatórios de adolescentes com excesso de peso: Uma revisão sistemática. Rev. Educ. Fís/UEM, v. 26, n. 4, p. 663-645, 2015. Disponível em: http://www.scielo.br/pdf/refuem/v26n4/1983-3083-refuem-2604-00633.pdf. Acesso em: 06 set. 2018.

FREITAS, L. K. P. et al. Obesidade em adolescentes e as políticas públicas de nutrição. Cienc. Saúde coletiva, $\quad$ v. $19, \quad$ n. $6, \quad 2014 . \quad$ Disponível em: http://www.scielo.br/scielo.php?script=sci_arttext\&pid=S1413-81232014000601755. Acesso em 19 jul. 2018.

HAMER, M. et al. Physical activity and inflammatory markers over 10 years follow up in men and women from the Whitehall II cohort study. Circulation, v. 126, n. 8, p. 928-933, 2012. 
Disponível em: https://www.ncbi.nlm.nih.gov/pmc/articles/PMC3890998/. Acesso em 15 out. 2018.

HONG, T. K. et al. Validity and reliability of a physical activity questionnaire for Vietnamese adolescents. International Journal of Behavioral Nutrition and Physical Activity, v. 9, n. 1, p. 93, 2012. Disponível em: https://www.ncbi.nlm.nih.gov/pubmed/22853177. Acesso em: 22 jul. 2018.

KAMAL, N. N; RAGY, M. M. The effects of exercise on C-reactive protein, insulin, leptin and some cardiometabolic risk factors in Egyptian children with or without metabolic syndrome. Diabetol Metab Syndr. v.4, n.27, 2012. Disponível em: https://www.ncbi.nlm.nih.gov/pmc/articles/PMC3536685/. Acesso em: 15 out. 2018.

KLENK, J. et al. Association of objectively measured physical activity with established and novel cardiovascular biomarkers in elderly subjects: every step counts. J Epidemiol Community Health, v.67, p. 194-197, 2012. Disponível em: https://jech.bmj.com/content/67/2/194.info. Acesso em: 15 out. 2018.

LANDE, M. B. et al. Elevated blood pressure, race/ethnicity, and C-reactive protein levels in children and adolescents. Pediatrics, v. 122, n. 6, p. 1252-1257, 2008. Disponível em: https://www.ncbi.nlm.nih.gov/pubmed/19047242 . Acesso em: 19 jul. 2018.

NORONHA, J. A. F. et al. Proteína C-reativa e sua relação com pressão arterial elevada em crianças e adolescentes com sobrepeso ou obesidade. Rev Paul Pediatr, v. 31, n. 3, p. 331337, 2013. Disponível em: http://www.scielo.br/pdf/rpp/v31n3/pt_0103-0582-rpp-31-0300331.pdf. Acesso em: 06 set. 2018.

ONIS. M. et al. Development of a WHO growth reference for school-aged children and adolescents. Bull World Health Organ. v. 85, n. 9, p. 660-667, 2007. Disponível em: https://www.ncbi.nlm.nih.gov/pubmed/18026621. Acesso em: 30 out. 2018.

PIRES et al. Obesidade: Paradigma da Disfunção Endotelial em Idade Pediátrica. Acta Med Port, v. 28; n. 2; p. 233-239, 2015. Disponivel em: https://www.researchgate.net/publication/278043746_Obesity_Paradigm_of_Endothelial_Dys function_in_Paediatric_Age_Groups. Acesso em: 19 jul. 2018.

QUEIROZ, C, O. Padrões de Atividade Física e Proteína C Reativa no Estudo Longitudinal de Saúde do Adulto (Elsa-Brasil). Dissertação (Mestrado em Biotecnologia em Saúde e Medicina Investigativa) - Fundação Oswaldo Cruz, Centro de Pesquisas Gonçalo Moniz. $\begin{array}{lllll}\text { Salvador. } & \text { p. } & 17 . & 2013 . & \text { Disponível }\end{array}$ https://www.arca.fiocruz.br/bitstream/icict/8397/2/Ciro\%20Oliveira\%20Queiroz\%20Padr\%C 3\%B5es\%20de\%20atividades...\%202013.pdf. Acesso em: 15 de out. 2018.

SAUCEDO-MOLINA, T. et al. Relacion entre el índice de masa corporal, la actividad fisica y los tiempos de comida en adolescentes mexicanos. Nutr Hosp, v. 32, n. 3, p. 1082-90, 2015. Disponível em: http://www.aulamedica.es/nh/pdf/9331.pdf. Acesso em: 23 jul. 2018.

SILVA, D.; LACERDA, A. P. Proteína C reativa de alta sensibilidade como biomarcador de risco na doença coronária. Rev Port Cardiol, v. 31; n. 11; p. 733-745, 2012. Disponível em: https://www.sciencedirect.com/science/article/pii/S0870255112001953. Acesso em: 19 jul. 2018.

STAIANO, A, E.; CALVERT, S, L. Exergames for PhysicalEducation Courses: Physical, Social, and Cognitive Benefits. Child Dev Perspect, v. 5, n. 2, p. 93-98, 2011. Disponível em: https://www.ncbi.nlm.nih.gov/pmc/articles/PMC3339488/. Acesso em: 23 jul. 2018.

TENÓRIO, M. C. M. et al. Atividade física e comportamento sedentário em adolescentes estudantes do ensino médio. Revista Brasileira de Epidemiologia. 2010; v. 13, n. 1, p. 105117. Disponivel em: http://www.scielo.br/scielo.php?script=sci_arttext\&pid=S1415- 
Impacto do Uso do Exergame Sobre o Risco Cardiovascular Avaliado Pela PCR Ultrassensível: Um Estudo com Adolescentes com Excesso de Peso

790X2010000100010. Acesso em: 19 jul. 2018.

VOJCIECHOWSKI, A. S. et al. Effects of exergame training on the health promotion of young adults. Fisioterapia em Movimento, v. 30, n. 1, p. 59-67, 2017. Disponível em: http://www.scielo.br/pdf/fm/v30n1/1980-5918-fm-30-01-00059.pdf. Acesso em: 06 set. 2018.

WHO. World Health Organization. Obesity and overweight. Feb. 2018a. Disponível em: http://www.who.int/news-room/fact-sheets/detail/obesity-and-overweight. Acesso em: 20 jul. 2018.

WHO. World Health Organization. Tenfold increase in childhood and adolescente obesity in four decades: new study by Imperial College London and WHO. Jun. 2018b.

Disponivel em: http://www.who.int/news-room/headlines/11-10-2017-tenfold-increase-inchildhood-and-adolescent-obesity-in-four-decades-new-study-by-imperial-college-london- andwho. Acesso em: 20 jul. 2018.

WHO. World Health Organization. Physical activity. Feb. 2018c. Disponível em: http://www.who.int/news-room/facts-in-pictures/detail/physical-activity. Acesso em: 23 jul. 2018. 